\title{
Differential effects of calcium antagonists on ABCG2/BCRP-mediated drug resistance and transport in SN-38-resistant HeLa cells
}

\author{
KOHJI TAKARA $^{1}$, MIKA MATSUBARA ${ }^{2}$, KAZUHIRO YAMAMOTO ${ }^{2}$, \\ TETSUYA MINEGAKI ${ }^{2}$, SHIGEHIKO TAKEGAMI ${ }^{3}$, MINORU TAKAHASHI ${ }^{1}$, \\ TERUYOSHI YOKOYAMA ${ }^{1}$ and KATSUHIKO OKUMURA ${ }^{1}$ \\ ${ }^{1}$ Department of Clinical Pharmaceutics, Faculty of Pharmaceutical Sciences, \\ Himeji Dokkyo University, Himeji 670-8524; Departments of ${ }^{2}$ Clinical Pharmacy, and \\ ${ }^{3}$ Analytical Chemistry, Faculty of Pharmaceutical Sciences, Kyoto Pharmaceutical University, \\ Misasagi, Yamashina-ku, Kyoto 607-8414, Japan
}

Received August 11, 2011; Accepted December 7, 2011

DOI: $10.3892 / \mathrm{mmr} .2011 .734$

\begin{abstract}
The effects of 9 calcium antagonists on ABCG2/ BCRP-mediated resistance and transport were examined in HeLa and SN-38-resistant HeLa (HeLa/SN100) cells, overexpressing ABCG2/BCRP. Sensitivity to mitoxantrone, an ABCG2/BCRP substrate, in HeLa/SN100 cells was significantly reversed by the coexistence of the calcium antagonists, except for diltiazem and verapamil. The accelerated transport activity of Hoechst33342, an ABCG2/BCRP substrate, in $\mathrm{HeLa} / \mathrm{SN} 100$ cells was significantly decreased by the presence of the calcium antagonists, except for diltiazem, nifedipine or verapamil, returning to the level of HeLa cells. The present study classifies the calcium antagonists into 3 categories: strong (benidipine, felodipine, nicardipine, nisoldipine and nitrendipine), moderate (amlodipine and nifedipine) and weak (diltiazem and verapamil) inhibitors of ABCG2/BCRP.
\end{abstract}

\section{Introduction}

The effectiveness of cancer chemotherapy has improved with the development of novel chemotherapeutic agents and molecular targeting agents $(1,2)$. However, multidrug resistance remains a serious problem in cancer chemotherapy $(3,4)$. Therefore, clarifying the mechanism of resistance to chemotherapeutic agents and establishing a methodology for the reversal of resistance are crucial for improving clinical outcomes in cancer chemotherapy.

Correspondence to: Dr Kohji Takara, Department of Clinical Pharmaceutics, Faculty of Pharmaceutical Sciences, Himeji Dokkyo University, 7-2-1 Kamiohno, Himeji 670-8524, Japan

E-mail: takara@gm.himeji-du.ac.jp

Key words: calcium antagonist, $\mathrm{ABCG} / \mathrm{BCRP}$, drug resistance, transport, HeLa
Among the reported resistance mechanisms, the ATP-binding cassette (ABC) transporters, i.e., ABCB1/MDR1 (P-glycoprotein), the ABCC family (MRPfamily), and ABCG2/ BCRP, are the main causes of resistance to chemotherapeutic agents $(3,5)$. These transporters have broad specificity for the recognition of substrates. Therefore, the effects of various agents on each transporter must be examined individually. In 1981, the inhibitory effect of verapamil on ABCB1/MDR1 function was reported (6), and then, the effects of calcium antagonists on $\mathrm{ABCB} 1 / \mathrm{MDR} 1$ were extensively investigated (7-10). We also examined the effects of calcium antagonists on ABCB1/MDR1-mediated transport and resistance, which varied according to the type of calcium antagonist used (11). However, little information is available concerning the effects of calcium antagonists on ABCG2/BCRP.

Previously, we established various types of resistant cells appropriate for examining the novel mechanism of resistance and techniques for reversing resistance $(12,13)$. One type, $\mathrm{HeLa} / \mathrm{SN} 100$, was selected from HeLa cells by exposure to an active metabolite of irinotecan hydrochloride, SN-38 (12). HeLa/SN100 cells overexpressed ABCG2/BCRP but not ABCB1/MDR1 (12). This is a useful tool for clarifying the details of the ABCG2/BCRP-mediated resistance mechanism and comparing it with other resistance mechanisms of paclitaxel-resistant (HeLa/TXL) or cisplatin-resistant (HeLa/ CDDP) cells established previously (13).

In the present study, we examined the effects of 9 calcium antagonists (Fig. 1) on ABCG2/BCRP-mediated resistance and transport in $\mathrm{HeLa} / \mathrm{SN} 100$ cells. The present findings were compared with previous reports, and the differential effects of calcium antagonists on ABCG2/BCRP were discussed.

\section{Materials and methods}

Chemicals. 7-Ethyl-10-hydroxycamptothecin (SN-38), an active metabolite of irinotecan hydrochloride, was a gift from Yakult Honsha Co., Ltd. (Tokyo, Japan). Amlodipine 

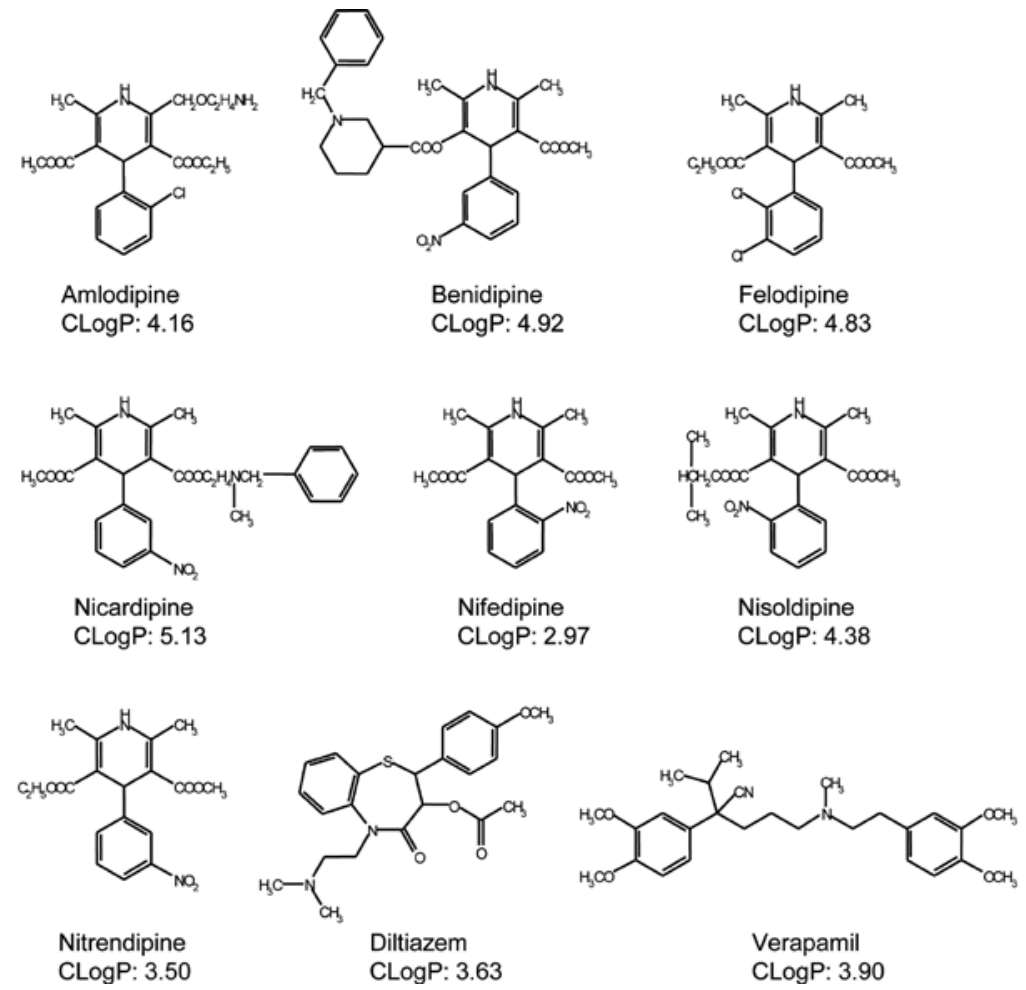

Figure 1. Chemical structures and CLogP of the calcium antagonists used in the study. The indices for lipophilicity of calcium antagonists, CLogP, were obtained from the SciFinder Scholar database (Chemical Abstract Service).

besylate, benidipine hydrochloride, nicardipine hydrochloride, nifedipine, nisoldipine, nitrendipine, diltiazem hydrochloride, verapamil hydrochloride, and bis-benzimide H-33342 trihydrochloride (Hoechst33342) was purchased from Wako Pure Chemical Industries, Ltd. (Osaka, Japan). Felodipine and mitoxantrone dihydrochloride were obtained from Sigma-Aldrich Chemical Co. (St. Louis, MO, USA). Tween-20 was obtained from ICN Biomedicals Inc. (Solon, OH, USA). 2-(4-Iodophenyl)-3-(4-nitrophenyl)-5-(2,4disulfophenyl)-2H-tetrazolium, monosodium salt (WST-1) and 1-methoxy-5-methylphenazinium methylsulfate were acquired from Dojindo Laboratories (Kumamoto).

Cells and cell culture. The human cervical carcinoma cell line HeLa was maintained in a culture medium consisting of Dulbecco's modified Eagle's medium (DMEM; Invitrogen Corp., Carlsbad, CA) supplemented with $10 \%$ heat-inactivated fetal bovine serum (lot no. $99 \mathrm{H} 2314$ or $40 \mathrm{~K} 2368$; Sigma-Aldrich) and $100 \mathrm{mg} / \mathrm{l}$ kanamycin sulfate (Invitrogen). $\mathrm{HeLa}$ cells were seeded into culture flasks, grown in a humidified atmosphere containing $5 \% \mathrm{CO}_{2}$ at $37^{\circ} \mathrm{C}$, and subcultured with $0.05 \%$ trypsin- $0.02 \%$ ethylenediamine$N, N, N^{\prime}, N^{\prime}$-tetraacetic acid (Invitrogen) at a density of $1 \times 10^{6}$ cells $/ 25 \mathrm{~cm}^{2}$ culture flasks. The HeLa/SN100 cells were previously established in our laboratory (12). HeLa/SN100 cells overexpressed $\mathrm{ABCG} 2 / \mathrm{BCRP}$ but not $\mathrm{ABCB} 1 / \mathrm{MDR} 1$, and showed resistance to irinotecan, topotecan and mitoxantrone (12). HeLa/SN100 cells were maintained in a similar manner as HeLa cells except that the DMEM contained $100 \mathrm{nM}$ SN-38. The passage numbers for the HeLa and HeLa/SN100 cells were $398-408$ and $15-24$, respectively.
WST-1 colorimetric assay. The effects of calcium antagonists on the sensitivity to mitoxantrone in HeLa and HeLa/SN100 cells were evaluated with a WST-1 assay (13-15). Cells (1x10 $/$ well) were seeded onto 96-well plates in $100 \mu 1$ DMEM without any drugs. After a $24 \mathrm{~h}$ pre-culture, the medium was aspirated off and exchanged for one containing mitoxantrone at various concentrations with or without the calcium antagonists at $0.1,1$, and $10 \mu \mathrm{M}$. After incubation for $72 \mathrm{~h}$ at $37^{\circ} \mathrm{C}$, the DMEM was exchanged for $110 \mu \mathrm{l}$ medium containing WST-1 reagent (10 $\mu \mathrm{l}$ WST-1 + $100 \mu$ l DMEM); 3 h later, the absorbance was determined at $450 \mathrm{~nm}$ with a reference wavelength of $620 \mathrm{~nm}$ by using a SpectraFluor ${ }^{\mathrm{TM}}$ microplate reader (Tecan Group Ltd., Männedorf, Switzerland). The 50\% growth inhibitory concentration $\left(\mathrm{IC}_{50}\right)$ of mitoxantrone was estimated according to the sigmoid inhibitory effect model, $\mathrm{E}=\mathrm{E}_{\max } \mathrm{x}\left[1-\mathrm{C}^{\gamma} /\left(\mathrm{C}^{\gamma}+\mathrm{IC}_{50}{ }^{\gamma}\right)\right]$, using the nonlinear least-squares fit method (Solver, Microsoft ${ }^{\circledR}$ Excel). $\mathrm{E}$ and $\mathrm{E}_{\max }$ represent the surviving fraction (percentage of control) and its maximum, respectively; $\mathrm{C}$ and $\gamma$ represent the concentration in the medium and the sigmoidicity factor, respectively. Relative sensitivity was defined by dividing the $\mathrm{IC}_{50}$ value for mitoxantrone in the control by that in the groups treated with the calcium antagonists.

Fluorescence microscopic imaging. HeLa ( $\left.1 \times 10^{5} / \mathrm{dish}\right)$ and $\mathrm{HeLa} / \mathrm{SN} 100\left(2 \times 10^{5} / \mathrm{dish}\right)$ cells were seeded onto a glassbottom dish (35 $\mathrm{mm}$ in diameter; Matsunami Glass Ind., Ltd., Osaka, Japan) in $2 \mathrm{ml} /$ well DMEM and incubated for $48 \mathrm{~h}$ in a humidified atmosphere containing $5 \% \mathrm{CO}_{2}$ at $37^{\circ} \mathrm{C}$. Cells were washed twice with warmed Hanks' balanced salt solution containing $25 \mathrm{mM}$ HEPES (HBSS), and then, a reaction was started by the addition of $2 \mathrm{ml}$ phenol red-free HBSS 
Table I. $\mathrm{IC}_{50}$ values for calcium antagonists in HeLa and HeLa/ SN100 cells.

\begin{tabular}{lcc}
\hline & \multicolumn{2}{c}{$\mathrm{IC}_{50}(\mu \mathrm{M})$} \\
\cline { 2 - 3 } $\begin{array}{l}\text { Calcium } \\
\text { antagonist }\end{array}$ & HeLa & HeLa/SN100 \\
\hline Amlodipine & $11.7 \pm 0.18$ & $11.3 \pm 0.13$ \\
Benidipine & $23.0 \pm 0.66$ & $21.8 \pm 0.23$ \\
Felodipine & $36.9 \pm 6.74$ & $54.5 \pm 1.26^{\mathrm{a}}$ \\
Nicardipine & $28.6 \pm 6.28$ & $30.7 \pm 0.57$ \\
Nifedipine & $99.9 \pm 0.16$ & $109 \pm 4.50$ \\
Nisoldipine & $30.3 \pm 0.78$ & $30.5 \pm 2.48$ \\
Nitrendipine & $32.5 \pm 1.86$ & $42.4 \pm 0.26^{\mathrm{b}}$ \\
Diltiazem & $90.3 \pm 2.43$ & $114 \pm 18.8$ \\
Verapamil & $21.4 \pm 0.83$ & $21.8 \pm 2.10$ \\
\hline
\end{tabular}

Each $\mathrm{IC}_{50}$ value is represented as the mean $\pm \mathrm{SE}(\mathrm{n}=4)$. HeLa/SN100, $\mathrm{SN}-38$-resistant HeLa cells. Significantly different from HeLa cells at ${ }^{\mathrm{a}} \mathrm{P}<0.05$ and ${ }^{\mathrm{b}} \mathrm{P}<0.01$, respectively.

containing $3 \mu \mathrm{M}$ Hoechst33342 with or without the calcium antagonists $(10 \mu \mathrm{M})$. The reaction was maintained at $37^{\circ} \mathrm{C}$, and fluorescence microscopic images were acquired at 0 and $15 \mathrm{~min}$ from initiation using a confocal laser scanning microscope (LSM510META ver. 4.2; Carl Zeiss AG, Oberkochen, Germany) (12).

Hoechst33342 transport experiments. In the accumulation experiments, HeLa and HeLa/SN100 cells (2x10 $/$ well) were seeded onto 24-well plates in $1 \mathrm{ml} /$ well DMEM and incubated for $48 \mathrm{~h}$ in a humidified atmosphere containing $5 \% \mathrm{CO}_{2}$ at $37^{\circ} \mathrm{C}(13,16)$. After pre-culture, cells were washed twice with warmed HBSS, and then, the accumulation experiments were started with the addition of $1 \mathrm{ml}$ fresh HBSS containing Hoechst33342 $(3 \mu \mathrm{M})$ or Hoechst33342 $(3 \mu \mathrm{M})$ plus calcium antagonist (final concentration, $0.1,1$, or $10 \mu \mathrm{M}$ ), and cells were further incubated for specific periods $(5,15,30,60,90$, or $120 \mathrm{~min}$ ) at $37^{\circ} \mathrm{C}$.

In the efflux experiments, HeLa and HeLa/SN100 cells were pre-cultured as described for the accumulation experiments. They were washed 3 times with warmed HBSS and were incubated in fresh HBSS containing $10 \mu \mathrm{M}$ Hoechst 33342 with or without the calcium antagonist for $60 \mathrm{~min}$ (loading time). After loading, HBSS was immediately removed from the wells and cells were washed rapidly twice with ice-cold HBSS. Efflux experiments were started with the addition of fresh warmed HBSS or HBSS containing calcium antagonist (final concentration, $0.1,1$, or $10 \mu \mathrm{M}$ ), and cells were further incubated for given periods $(1,5,15,30$, or $60 \mathrm{~min})$ at $37^{\circ} \mathrm{C}$.

Both the accumulation and efflux experiments were stopped by aspirating the HBSS from the well, followed by washing the cells 3 times with ice-cold phosphate-buffered saline. After the experiments were stopped, cells were solubilized with $1 \mathrm{ml}$ phosphate-buffered saline containing $0.1 \%$ Tween-20. Aliquots (200 $\mu \mathrm{l})$ of 2 -fold diluted cell lysate were transferred to 96-well black plates, and the fluorescence intensity of Hoechst33342 was measured with an excitation

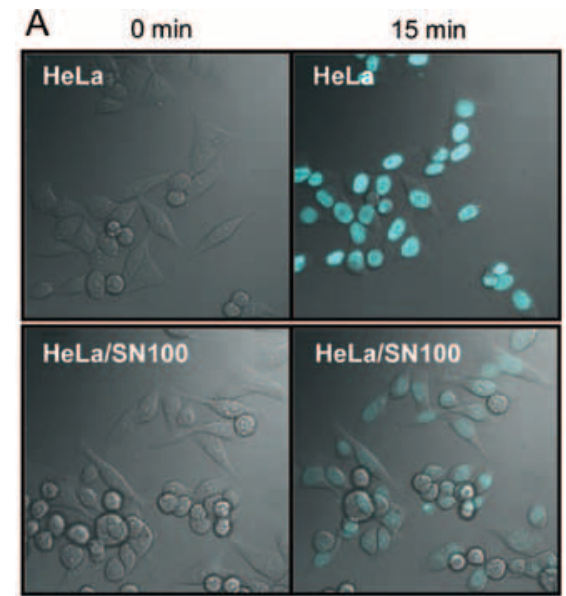

B At 15 min from initiation

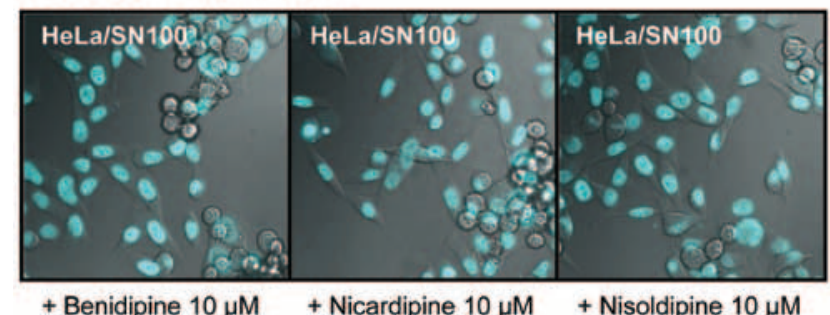

Figure 2. Cellular distribution of Hoechst33342. HeLa and SN-38-resistant $\mathrm{HeLa}(\mathrm{HeLa} / \mathrm{SN} 100)$ cells were pre-cultured for $48 \mathrm{~h}$ in a humidified atmosphere containing $5 \% \mathrm{CO}_{2}$ at $37^{\circ} \mathrm{C}$. (A) $\mathrm{HeLa}$ and $\mathrm{HeLa} / \mathrm{SN} 100$ cells were incubated with phenol red-free Hanks' balanced salt solution containing $3 \mu \mathrm{M}$ Hoechst33342, and images were acquired at 0 and $15 \mathrm{~min}$. (B) Effects of the coexistence of benidipine, nicardipine, and nisoldipine at $10 \mu \mathrm{M}$ for 15 min were demonstrated in HeLa/SN100 cells.

wavelength of $340 \mathrm{~nm}$ and emission wavelength of $465 \mathrm{~nm}$ by using a microplate reader SpectraFluor ${ }^{\mathrm{TM}}$ (Tecan). Protein content was determined by the Lowry method (17), and bovine serum albumin (Sigma-Aldrich) was used as the standard.

Statistical analysis. Data were represented as the mean \pm S.E. Comparisons between 2 and among 3 or more groups were performed using the Student's unpaired t-test and the repeated one-way analysis of variance followed by calculation of Scheffe's F, respectively. A P-value of less than 0.05 (twotailed) was considered significant. The correlation analysis was performed using Pearson's correlation coefficient (r).

\section{Results}

Effects of calcium antagonists on sensitivity to mitoxantrone. The $\mathrm{IC}_{50}$ values for calcium antagonists were more than $20 \mu \mathrm{M}$ in both cells, whereas those for amlodipine were about $11 \mu \mathrm{M}$ (Table I). Except for felodipine and nitrendipine, the calcium antagonists showed comparable inhibitory effects in both cells. Table II shows the $\mathrm{IC}_{50}$ values for mitoxantrone in HeLa and HeLa/SN100 cells in the absence or presence of the calcium antagonists. The $\mathrm{IC}_{50}$ value for mitoxantrone was 20.8 -fold higher in HeLa/SN100 than in HeLa cells. This value was significantly decreased by the coexistence of benidipine, felodipine, nicardipine, nifedipine, nisoldipine and nitrendipine in a concentration-dependent manner. The coexistence of 
Table II. IC $_{50}$ values for mitoxantrone in HeLa and HeLa/SN100 cells in the absence or presence of calcium antagonists.

\begin{tabular}{|c|c|c|c|c|c|}
\hline & & \multicolumn{2}{|c|}{ HeLa cells } & \multicolumn{2}{|c|}{ HeLa/SN100 cells } \\
\hline & & $\mathrm{IC}_{50}(\mathrm{nM})$ & $\mathrm{RS}$ & $\mathrm{IC}_{50}(\mathrm{nM})$ & $\mathrm{RS}$ \\
\hline \multicolumn{2}{|l|}{ Control } & $15.7 \pm 1.45$ & - & $327 \pm 7.07$ & - \\
\hline \multirow[t]{3}{*}{ Amlodipine } & $0.1 \mu \mathrm{M}$ & $18.9 \pm 2.31$ & 0.83 & $216 \pm 8.72^{\mathrm{b}}$ & 1.51 \\
\hline & $1 \mu \mathrm{M}$ & $15.3 \pm 1.88$ & 1.03 & $240 \pm 22.8^{\mathrm{b}}$ & 1.36 \\
\hline & $10 \mu \mathrm{M}$ & ND & - & ND & - \\
\hline \multirow[t]{3}{*}{ Benidipine } & $0.1 \mu \mathrm{M}$ & $6.01 \pm 1.08^{\mathrm{b}}$ & 2.61 & $132 \pm 16.8^{\mathrm{b}}$ & 2.48 \\
\hline & $1 \mu \mathrm{M}$ & $11.4 \pm 1.86$ & 1.37 & $111 \pm 16.8^{\mathrm{b}}$ & 2.94 \\
\hline & $10 \mu \mathrm{M}$ & $7.70 \pm 1.56^{\mathrm{a}}$ & 2.04 & $37.1 \pm 3.68^{b}$ & 8.82 \\
\hline \multirow[t]{3}{*}{ Felodipine } & $0.1 \mu \mathrm{M}$ & $15.3 \pm 2.42$ & 1.03 & $221 \pm 28.4^{\mathrm{a}}$ & 1.48 \\
\hline & $1 \mu \mathrm{M}$ & $14.2 \pm 1.38$ & 1.10 & $183 \pm 18.4^{\mathrm{b}}$ & 1.79 \\
\hline & $10 \mu \mathrm{M}$ & $4.04 \pm 0.27^{b}$ & 3.88 & $95.4 \pm 9.50^{b}$ & 3.43 \\
\hline \multirow[t]{3}{*}{ Nicardipine } & $0.1 \mu \mathrm{M}$ & $12.9 \pm 0.62$ & 1.22 & $190 \pm 13.4^{\mathrm{b}}$ & 1.72 \\
\hline & $1 \mu \mathrm{M}$ & $15.2 \pm 1.36$ & 1.03 & $199 \pm 11.1^{\mathrm{b}}$ & 1.65 \\
\hline & $10 \mu \mathrm{M}$ & $2.28 \pm 0.39^{\mathrm{b}}$ & 6.88 & $45.9 \pm 0.66^{\mathrm{b}}$ & 7.14 \\
\hline \multirow[t]{3}{*}{ Nifedipine } & $0.1 \mu \mathrm{M}$ & $13.2 \pm 0.74$ & 1.19 & $215 \pm 14.8^{b}$ & 1.53 \\
\hline & $1 \mu \mathrm{M}$ & $11.4 \pm 0.31$ & 1.38 & $201 \pm 29.9^{b}$ & 1.63 \\
\hline & $10 \mu \mathrm{M}$ & $14.4 \pm 0.91$ & 1.09 & $164 \pm 6.64^{b}$ & 1.99 \\
\hline \multirow[t]{3}{*}{ Nisoldipine } & $0.1 \mu \mathrm{M}$ & $12.7 \pm 2.79$ & 1.24 & $256 \pm 36.0$ & 1.28 \\
\hline & $1 \mu \mathrm{M}$ & $18.6 \pm 1.24$ & 0.84 & $175 \pm 30.1^{\mathrm{b}}$ & 1.87 \\
\hline & $10 \mu \mathrm{M}$ & $3.66 \pm 0.57^{b}$ & 4.30 & $40.6 \pm 3.20^{b}$ & 8.06 \\
\hline \multirow[t]{3}{*}{ Nitrendipine } & $0.1 \mu \mathrm{M}$ & $38.2 \pm 1.54^{\mathrm{b}}$ & 0.41 & $217 \pm 19.9^{b}$ & 1.51 \\
\hline & $1 \mu \mathrm{M}$ & $21.9 \pm 0.98^{\mathrm{a}}$ & 0.72 & $159 \pm 19.9^{b}$ & 2.07 \\
\hline & $10 \mu \mathrm{M}$ & $12.3 \pm 0.76$ & 1.27 & $89.1 \pm 4.02^{b}$ & 3.68 \\
\hline \multirow[t]{3}{*}{ Diltiazem } & $0.1 \mu \mathrm{M}$ & $15.1 \pm 1.93$ & 1.04 & $321 \pm 50.4$ & 1.02 \\
\hline & $1 \mu \mathrm{M}$ & $16.0 \pm 2.28$ & 0.98 & $415 \pm 42.5$ & 0.79 \\
\hline & $10 \mu \mathrm{M}$ & $14.4 \pm 1.26$ & 1.09 & $209 \pm 43.8$ & 1.57 \\
\hline \multirow[t]{3}{*}{ Verapamil } & $0.1 \mu \mathrm{M}$ & $22.7 \pm 2.10^{\mathrm{b}}$ & 0.69 & $40 \pm 30.2$ & 0.82 \\
\hline & $1 \mu \mathrm{M}$ & $16.0 \pm 1.37$ & 0.98 & $292 \pm 42.2$ & 1.12 \\
\hline & $10 \mu \mathrm{M}$ & $14.4 \pm 0.76$ & 1.09 & $257 \pm 41.7$ & 1.28 \\
\hline
\end{tabular}

Each $\mathrm{IC}_{50}$ value is represented as mean $\pm \mathrm{SE}(\mathrm{n}=4)$. $\mathrm{RS}$, relative sensitivity (the ratio of $\mathrm{IC}_{50}$ values for mitoxantrone in the control divided by that in the groups treated with calcium antagonists). ND, not determined for cytotoxicity by continuous exposure to amlodipine. HeLa/SN100, $\mathrm{SN}-38$-resistant HeLa cells. Significantly different from the respective control at ${ }^{\mathrm{a}} \mathrm{P}<0.05$ and ${ }^{\mathrm{b}} \mathrm{P}<0.01$, respectively.

amlodipine also significantly decreased this sensitivity at 0.1 and $1 \mu \mathrm{M}$. The sensitivity to mitoxantrone of HeLa/SN100 cells was not affected by the presence of diltiazem or verapamil.

In the case of HeLa cells, the coexistence of benidipine, felodipine, nicardipine and nisoldipine decreased their $\mathrm{IC}_{50}$ value substantially, although the $\mathrm{IC}_{50}$ value was increased by the presence of nitrendipine and verapamil. The sensitivity to mitoxantrone of HeLa cells was not influenced by the presence of amlodipine, nifedipine, or diltiazem.

Transport characteristics of Hoechst33342. The cellular kinetics of Hoechst33342 differed between HeLa and HeLa/ SN100 cells, being confirmed by the cellular distribution of Hoechst33342 as determined from the fluorescence micro- graphs (Fig. 2). The decreased cellular distribution in HeLa/ SN100 cells was reversed by the addition of $10 \mu \mathrm{M}$ benidipine, nicardipine and nisoldipine.

Effects of calcium antagonists on the time course of Hoechst 33342 cellular accumulation. Fig. 3 shows the time course of Hoechst33342 accumulation in HeLa/SN100 cells in the presence or absence of calcium antagonists at 0.1 , 1 and $10 \mu \mathrm{M}$. The accumulation of Hoechst33342 in HeLa/ SN100 cells was markedly lower than that in HeLa cells (data not shown). The decreased accumulation was significantly increased by the presence of amlodipine, benidipine, felodipine, nicardipine, nisoldipine and nitrendipine, and it recovered to the level in HeLa cells (accumulation in steady 


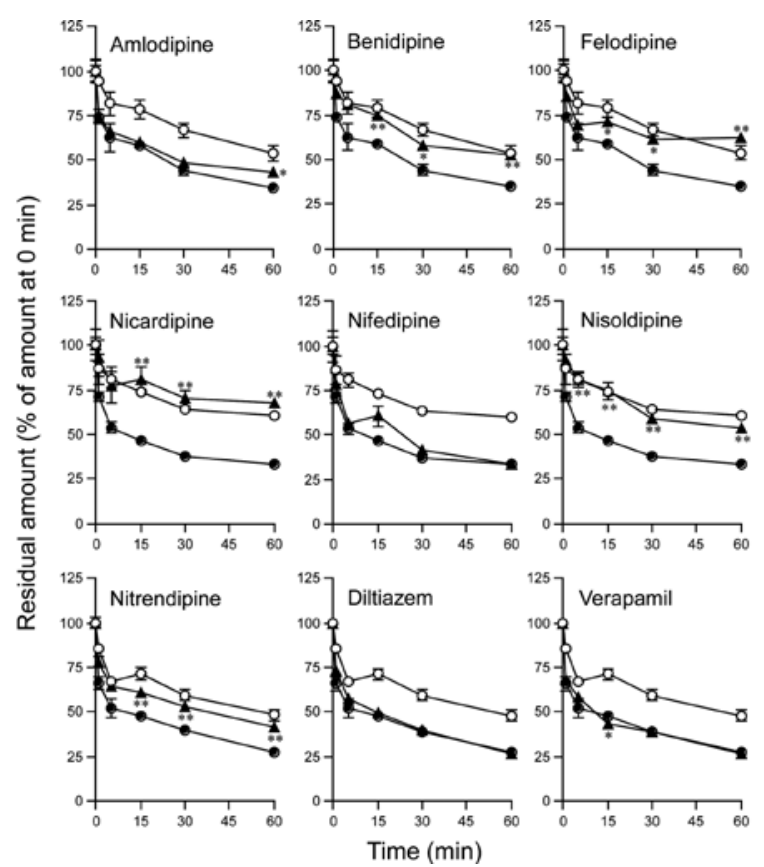

Figure 3. Time course of Hoechst33342 accumulation. SN-38-resistant HeLa (HeLa/SN100) cells were incubated with $3 \mu \mathrm{M}$ Hoechst33342 in the absence (o) or presence $(\bullet, 0.1 \mu \mathrm{M} ; \boldsymbol{\wedge}, 1 \mu \mathrm{M} ; \boldsymbol{\bullet}, 10 \mu \mathrm{M})$ of calcium antagonists for the indicated times at $37^{\circ} \mathrm{C}$. Each point represents the mean $\pm \mathrm{SE}(\mathrm{n}=3)$. Significantly different from control at the corresponding time points at ${ }^{*} \mathrm{P}<0.05$ and ${ }^{* *} \mathrm{P}<0.01$, respectively

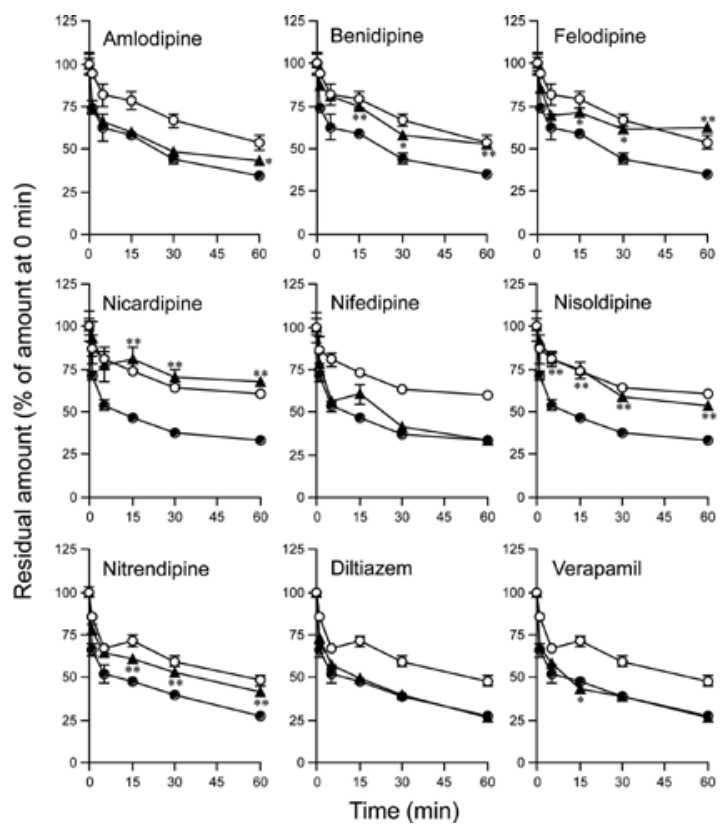

Figure 4. Time course of Hoechst33342 efflux. After cells were incubated with $3 \mu \mathrm{M}$ Hoechst33342 in the absence or presence of $10 \mu \mathrm{M}$ calcium antagonists for $60 \mathrm{~min}$ at $37^{\circ} \mathrm{C}$, they were washed twice in ice-cold Hanks' balanced salt solution (HBSS) and incubated with warmed HBSS in the absence or presence of $10 \mu \mathrm{M}$ calcium antagonists for the indicated times. $\circ, \mathrm{HeLa} ; \bullet$, SN-38-resistant HeLa (HeLa/SN100); $\Delta, \mathrm{HeLa} / \mathrm{SN} 100+10 \mu \mathrm{M}$ calcium antagonists. Each point represents the mean $\pm \mathrm{SE}(\mathrm{n}=3)$. Significantly different from $\mathrm{HeLa} / \mathrm{SN} 100$ cells in the absence of calcium antagonists at the corresponding time points at ${ }^{*} \mathrm{P}<0.05$ and ${ }^{* *} \mathrm{P}<0.01$, respectively.

state, $\sim 6 \mathrm{nmol} / \mathrm{mg}$ protein). However, the decreased accumulation of Hoechst 33342 was not affected by the presence
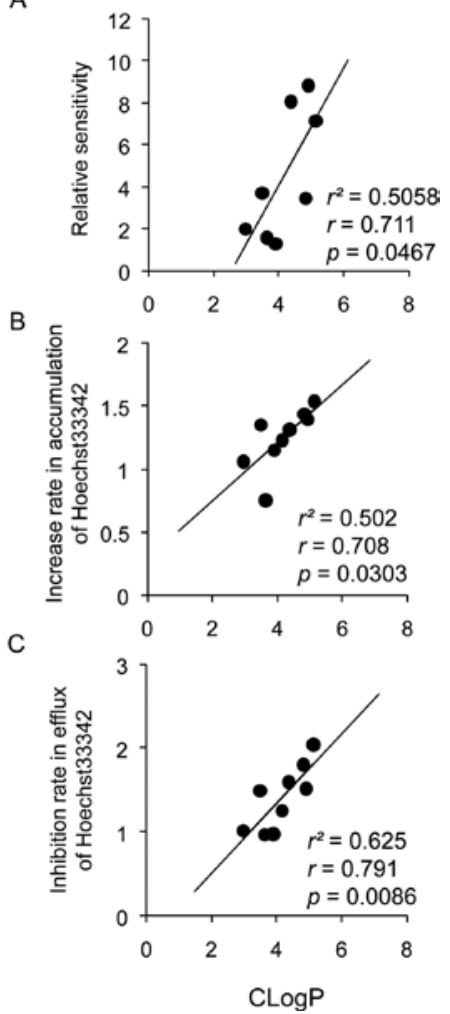

Figure 5. Correlation between the change in sensitivity to mitoxantrone or transport activity of Hoechst33342 and lipophilicity of calcium antagonists. The indices for lipophilicity of calcium antagonists, CLogP, were obtained from the SciFinder Scholar database (Chemical Abstract Service). (A) Relative sensitivity, except for amlodipine, is represented as the $\mathrm{IC}_{50}$ value for mitoxantrone in the control divided by that in the groups treated with $10 \mu \mathrm{M}$ calcium antagonists, as shown in Table II. (B) The rate of alteration in the transport activity of ABCG2/BCRP was indicated as the ratio of the accumulation or (C) efflux of Hoechst 33342 for $1 \mathrm{~h}$ in the treatment group to that in the control group. The correlation analysis was performed using Pearson's correlation coefficient (r).

of nifedipine or verapamil. In addition, diltiazem showed a tendency to decrease the accumulation of Hoechst33342.

Effects of calcium antagonists on the time course of Hoechst33342 efflux. Fig. 4 shows the time course of cellular residual amounts of Hoechst33342 after efflux from HeLa and HeLa/SN100 cells. The residual ratio of Hoechst33342 in $\mathrm{HeLa} / \mathrm{SN} 100$ cells was significantly lower than that in HeLa cells. This was recovered by the presence of benidipine, felodipine, nicardipine, nisoldipine and nitrendipine at $10 \mu \mathrm{M}$ and was returned to the level in HeLa cells. Amlodipine tended to increase the residual amount of Hoechst33342 in HeLa/SN100 cells, but nifedipine, diltiazem and verapamil did not affect it.

Relationship between the change in sensitivity to or transport activity of mitoxantrone and the molecular characteristics of the calcium antagonists. The index for hydrophobicity of the compounds, i.e. CLogP, showed a strong correlation with the relative sensitivity or change in transport activity of Hoechst33342 (Fig. 5, P<0.05). In addition, the molecular weight of the calcium antagonists showed no significant correlation with the relative sensitivity or the change in transport activity of Hoechst33342 (data not shown). 
Table III. Summary of the inhibitory effect of calcium antagonists on ABCG2/BCRP and ABCB1/MDR1.

Inhibitory effect on ABCG2/BCRP

Zhou et al

Present study

(20)
Zhang et al

(19)

\begin{tabular}{ll}
\hline Amlodipine & Moderate \\
Benidipine & Strong \\
Felodipine & Strong \\
Nicardipine & Strong \\
Nifedipine & Moderate \\
Nisoldipine & Strong \\
Nitrendipine & Strong \\
Diltiazem & Weak \\
Verapamil & Weak \\
\hline
\end{tabular}

Inhibitory effect on $\mathrm{ABCB} 1 / \mathrm{MDR} 1$

Katoh et al

(21)

Takara et al

(11)

\section{Discussion}

HeLa/SN100 cells were previously established by exposure to $\mathrm{SN}-38$, an active metabolite of irinotecan hydrochloride, in our laboratory (12). HeLa/SN100 cells overexpressed ABCG2/ BCRP but not ABCB1/MDR1 (12) and exhibited a 20-fold resistance to mitoxantrone, a substrate for $\mathrm{ABCG} 2 / \mathrm{BCRP}$ (Table II). However, resistance to cisplatin, a representative non-substrate for ABCG2/BCRP, was not observed in the $\mathrm{HeLa} / \mathrm{SN} 100$ cells (12). The transport activity of Hoechst33342, a substrate for $\mathrm{ABCG} 2 \mathrm{BCRP}$, was also more accelerated in $\mathrm{HeLa} / \mathrm{SN} 100$ than in HeLa cells (Figs. 2-4). Therefore, HeLa/ SN100 cells are a useful tool for evaluating the reversal of ABCG2/BCRP-mediated resistance, although one may not be able to estimate the effects in vivo based on only the present findings in vitro.

First, the growth inhibitory effects of calcium antagonists were examined in HeLa and HeLa/SN100 cells. The $\mathrm{IC}_{50}$ values for calcium antagonists were more than $20 \mu \mathrm{M}$ in both cells, whereas those for amlodipine were about $11 \mu \mathrm{M}$. Except for felodipine and nitrendipine, calcium antagonists showed comparable inhibitory effects in both cells (Table I), suggesting the possibility of a non-substrate for ABCG2/ BCRP. However, there are inconsistent reports that dihydropyrimidine calcium antagonists are a substrate for ABCG2/ BCRP (18), and detailed examinations may be needed.

Next, the reversal effects of calcium antagonists on ABCG2/ BCRP-mediated resistance were examined (Table II). Except for diltiazem and verapamil, the calcium antagonists significantly reversed the sensitivity to mitoxantrone in HeLa/SN100 cells. This reversal activity was ranked as follows: benidipine $\sim$ nicardipine $>$ nisoldipine $>$ felodipine $\sim$ nitrendipine $>$ amlodipine $\sim$ nifedipine $>>$ diltiazem $\sim$ verapamil. In addition, the effects of the calcium antagonists on ABCG2/BCRP-mediated transport were examined (Figs. 2-4). In light of the findings of accumulation and efflux studies, the inhibitory activity of the 9 calcium antagonists on ABCG2/BCRP-mediated transport was ranked as follows: benidipine $\sim$ nicardipine $\sim$ nisoldipine $>$ felodipine $\sim$ nitrendipine $>$ amlodipine $>$ nifedipine. Both diltiazem and verapamil had a very weak effect on ABCG2/
BCRP. Zhang et al (19) reported that the inhibitory activity of nicardipine was strong and that of nifedipine was weak. In addition, diltiazem and verapamil were reported to hardly inhibit ABCG2/BCRP. Nicardipine and nitrendipine were also reported to reverse the accumulation of and sensitivity to mitoxantrone in ABCG2/BCRP-overexpressing cells, whereas nifedipine had hardly any affect on them (20). Consequently, these findings suggest that some calcium antagonists have inhibitory activity against $\mathrm{ABCG}$ /BCRP and their potency differs. In addition, the change in sensitivity to mitoxantrone by calcium antagonists showed a positive correlation with the change in the transport activity of Hoechst33342 in HeLa/ SN100 cells (data not shown), demonstrating that HeLa/ SN100 cells are an effective tool for evaluating the activity of test compounds on ABCG2/BCRP-mediated resistance and transport. However, an exception was also found in nifedipine, which reversed the sensitivity to mitoxantrone (Table II) but had no effects on the transport activity of Hoechst 33342 (Figs. 3 and 4). This may be explained by the difference in the affinity of nifedipine, mitoxantrone and Hoechst33342 to ABCG2/BCRP.

Many researchers have reported that calcium antagonists inhibit ABCB1/MDR1 (7-10). Katoh et al (21) demonstrated that benidipine and nicardipine strongly inhibited ABCB1/MDR1, whereas nifedipine showed weak activity among the 13 dihydropyridine calcium antagonists used. In addition, the reversal effects of calcium antagonists on resistance to the ABCB1/ MDR1 substrate, i.e., vinblastine or paclitaxel, have been reported using ABCB1/MDR1-overexpressing cells, demonstrating inhibitory activity as follows: verapamil $>$ benidipine $>$ nicardipine $>$ diltiazem $>$ nifedipine $\approx$ nisoldipine $\approx$ nitrendipine (11). In the same study, the inhibitory activity on ABCB1/ MDR1-mediated transport was ranked as follows: nicardipine $\approx$ benidipine $>$ verapamil $>$ nisoldipine $>$ nitrendipine $>$ diltiazem $>$ nifedipine (11). Collectively, benidipine and nicardipine were suggested to have strong inhibitory activity on both ABCG2/ BCRP and ABCB1/MDR1, but nifedipine had weak activity on both (Table III). In addition, diltiazem was considered to be non-effective on both ABCG2/BCRP and ABCB1/MDR1. Consequently, the activity of calcium antagonists on ABCG2/ 
BCRP and ABCB1/MDR1 was, at least in part, suggested to be quantitatively and qualitatively similar. However, verapamil had no marked activity on ABCG2/BCRP, whereas it strongly inhibited ABCB1/MDR1 (Table III). This difference may provide useful information for analyzing the function and substrate specificity for ABCG2/BCRP and ABCB1/MDR1.

Finally, the reasons for the differences in inhibitory activity among calcium antagonists were examined. The molecular weight of the calcium antagonists showed a weak correlation with sensitivity to mitoxantrone or transport activity of Hoechst33342 (data not shown), suggesting that they are not significant factors in determining the inhibitory activity on ABCG2/BCRP. However, the lipophilicity of calcium antagonists, i.e., CLogP, taken from the SciFinder Scholar database (Chemical Abstract Service), showed a significant positive correlation with both sensitivity to mitoxantrone and transport activity of Hoechst33342 (Fig. 5), implying that the strength of the inhibitory effect was determined by membrane permeability of the compounds. Thus, the lipophilicity is significant in determining the inhibitory activity on ABCG2/ BCRP. All calcium antagonists that inhibited ABCG2/BCRP included a dihydropyridine structure. The compounds having a pyridine ring have been reported to inhibit the function of ABCG2/BCRP (20). In light of the present findings and the previous study, a heterocyclic compound including nitrogen might affect substrate recognition by $\mathrm{ABCG} 2 / \mathrm{BCR}$. In addition, in the case of calcium antagonists having a dihydropyridine structure, the side-chain of the dihydropyridine structure affected the inhibitory activity of ABCG2/BCRP, since the side-chains of calcium antagonists with strong inhibitory activity are larger in molecular weight and molecular surface area than those with weak inhibitory activity. Zhang et al (19) suggested that the side-chain of a heterocyclic compound affected the inhibitory activity of ABCG2/ BCRP. Consequently, if calcium antagonists are used as lead compounds, modifying the side-chain binding to the dihydropyridine structure may be a useful strategy for developing inhibitory activity against ABCG2/BCRP.

In conclusion, the present study classifies these calcium antagonists into 3 categories, i.e., strong, moderate and weak inhibitors of ABCG2/BCRP. The strong inhibitors include benidipine, felodipine, nicardipine, nisoldipine, and nitrendipine. The moderate inhibitors include amlodipine and nifedipine. Diltiazem and verapamil are categorized as the weak inhibitors. In addition, these characteristics are, at least in part, quantitatively and qualitatively comparable to the inhibitory effects on ABCB1/MDR1.

\section{Acknowledgements}

This study was supported in part by a Grant-in-aid for Young Scientists from the Ministry of Education, Culture, Sports, Science and Technology of Japan.

\section{References}

1. Schrama D, Reisfeld RA and Becker JC: Antibody targeted drugs as cancer therapeutics. Nat Rev Drug Discov 5: 147-159, 2006.
2. Le Toumeau C, Faivre S and Raymond E: New developments in multitargeted therapy for patients with solid tumors. Cancer Treat Rev 34: 37-48, 2008.

3. Takara K, Sakaeda T and Okumura K: An update on overcoming MDR1-mediated multidrug resistance in cancer. Curr Pharm Des 12: 273-286, 2006.

4. Mimeault M, Hauke R and Batra SK: Recent advances on the molecular mechanisms involved in the drug resistance of cancer cells and novel targeting therapies. Clin Pharmacol Ther 83: 673-691, 2008.

5. Eckford PD and Sharom FJ: ABC efflux pump-based resistance to chemotherapy drugs. Chem Rev 109: 2989-3011, 2009.

6. Tsuruo T, Iida H, Tsukagoshi S and Sakurai Y: Overcoming of vincristine resistance in P388 leukemia in vivo and in vitro through enhanced cytotoxicity of vincristine and vinblastine by verapamil. Cancer Res 41: 1967-1972, 1981.

7. Shudo N, Mizoguchi T, Kiyosue T, Arita M, Yoshimura A, Seto $\mathrm{K}$, Sakoda R and Akiyama S: Two pyridine analogues with more effective ability to reverse multidrug resistance and with lower calcium channel blocking activity than their dihydropyridine counterparts. Cancer Res 50: 3055-3061, 1990.

8. Jaffrézou JP, Herbert JM, Levade T, Gau MN, Chatelain P and Laurent G: Reversal of multidrug resistance by calcium channel blocker SR33557 without photoaffinity labeling of P-glycoprotein. J Biol Chem 266: 19858-19864, 1991.

9. Takara K, Kakumoto M, Tanigawara Y, Funakoshi J, Sakaeda T and Okumura K: Interaction of digoxin with antihypertensive drugs via MDR1. Life Sci 70: 1491-1500, 2002.

10. Viale M, Cordazzo C, de Totero D, Budriesi R, Rosano C, Leoni A, Ioan P, Aiello C, Croce M, Andreani A, Rambaldi M, Russo P, Chiarini A and Spinelli D: Inhibition of MDR1 activity and induction of apoptosis by analogues of nifedipine and diltiazem: an in vitro analysis. Invest New Drugs 29: 98-109, 2011.

11. Takara K, Sakaeda T, Tanigawara Y, Nishiguchi K, Ohmoto N, Horinouchi M, Komada F, Ohnishi N, Yokoyama T and Okumura K: Effects of $12 \mathrm{Ca}^{2+}$ antagonists on multidrug resistance, MDR1-mediated transport and MDR1 mRNA expression. Eur J Pharm Sci 16: 159-165, 2002.

12. Takara K, Kitada N, Yoshikawa E, Yamamoto K, Horibe S, Sakaeda T, Nishiguchi K, Ohnishi N and Yokoyama T: Molecular changes to HeLa cells on continuous exposure to SN-38, an active metabolite of irinotecan hydrochloride. Cancer Lett 278: 88-96, 2009.

13. Takara K, Obata Y, Yoshikawa E, Kitada N, Sakaeda T, Ohnishi N and Yokoyama T: Molecular changes to HeLa cells on continuous exposure to cisplatin or paclitaxel. Cancer Chemother Pharmacol 58: 785-793, 2006.

14. Takara K, Sakaeda T, Yagami T, Kobayashi H, Ohmoto N, Horinouchi M, Nishiguchi K and Okumura K: Cytotoxic effects of 27 anticancer drugs in HeLa and MDR1-overexpressing derivative cell lines. Biol Pharm Bull 25: 771-778, 2002.

15. Takara K, Horibe S, Obata Y, Yoshikawa E, Ohnishi N and Yokoyama T: Effects of 19 herbal extracts on the sensitivity to paclitaxel or 5-fluorouracil in HeLa cells. Biol Pharm Bull 28: 138-142, 2005

16. Takara K, Tsujimoto M, Ohnishi N and Yokoyama T: Digoxin up-regulates MDR1 in human colon carcinoma Caco-2 cells. Biochem Biophys Res Commun 292: 190-194, 2002.

17. Lowry OH, Rosebrough NJ, Farr AL and Randall RJ: Protein measurement with the Folin phenol reagent. J Biol Chem 193: 265-275, 1951.

18. Shukla S, Robey RW, Bates SE and Ambudkar SV: The calcium channel blockers, 1,4-dihydropyridines, are substrates of the multidrug resistance-linked $\mathrm{ABC}$ drug transporter, ABCG2. Biochemistry 45: 8940-8951, 2006.

19. Zhang Y, Gupta A, Wang H, Zhou L, Vethanayagam RR, Unadkat JD and Mao Q: BCRP transports dipyridamole and is inhibited by calcium channel blockers. Pharm Res 22: 2023-2034, 2005.

20. Zhou XF, Yang X, Wang Q, Coburn RA and Morris ME: Effects of dihydropyridines and pyridines on multidrug resistance mediated by breast cancer resistance protein: in vitro and in vivo studies. Drug Metab Dispos 33: 1220-1228, 2005.

21. Katoh M, Nakajima M, Yamazaki $H$ and Yokoi T: Inhibitory potencies of 1,4-dihydropyridine calcium antagonists to P-glycoprotein-mediated transport: comparison with the effects on CYP3A4. Pharm Res 17: 1189-1197, 2000 